\title{
Pilot scale photobioreactor system for land-based macroalgae cultivation
}

\author{
Tonia Annick Schmitz ${ }^{1}\left[\right.$ ] Eckhard Kraft ${ }^{1}$
}

Received: 2 January 2021 / Revised and accepted: 27 September 2021 / Published online: 21 October 2021

(c) The Author(s) 2021

\begin{abstract}
Marine macroalgae such as Ulva intestinalis have promising properties as feedstock for cosmetics and pharmaceuticals. However, since the quantity and quality of naturally grown algae vary widely, their exploitability is reduced - especially for producers in high-priced markets. Moreover, the expansion of marine or shore-based cultivation systems is unlikely in Europe, since promising sites either lie in fishing zones, recreational areas, or natural reserves. The aim was therefore to develop a closed photobioreactor system enabling full control of abiotic environmental parameters and an effective reconditioning of the cultivation medium in order to produce marine macroalgae at sites distant from the shore. To assess the feasibility and functionality of the chosen technological concept, a prototypal plant has been implemented in central Germany - a site distant from the sea. Using a newly developed, submersible LED light source, cultivation experiments with Ulva intestinalis led to growth rates of $7.72 \pm 0.04 \%$ day $^{-1}$ in a cultivation cycle of 28 days. Based on the space demand of the production system, this results in fresh mass productivity of $3.0 \mathrm{~kg} \mathrm{~m}^{-2}$, respectively, of $1.1 \mathrm{~kg} \mathrm{~m}^{-2}$ per year. Also considering the ratio of biomass to energy input amounting to $2.76 \mathrm{~g} \mathrm{kWh}^{-1}$, significant future improvements of the developed photobioreactor system should include the optimization of growth parameters, and the reduction of the system's overall energy demand.
\end{abstract}

Keywords Macroalgae $\cdot$ Photobioreactor $\cdot$ Ulva intestinalis $\cdot$ LED light source $\cdot$ Production system $\cdot$ Closed system cultivation

\section{Introduction}

The green alga Ulva intestinalis is a typical representative of Chlorophyta and grows on rocky ground or as an epiphyte in the intertidal zones of nutrient-rich marine waters (Budd and Pizzola 2008). Appreciated for its high content of iron, magnesium, and selenium (Circuncisão et al. 2018), it is currently being cultivated for human consumption in Korea, Japan, India, and Indonesia (FAO 2018). Moreover, $U$. intestinalis appears highly promising as raw material for cosmetics and pharmaceuticals. Its antioxidant, fungicidal, antibiotic, antiviral, and anticarcinogenic properties have been assessed in numerous scientific studies (e.g., Farasat et al. 2014; Murphy et al. 2014; Kosanić et al. 2015). The biochemical substance responsible for the mentioned effects is called ulvan and consists of sulfated polysaccharides only

Tonia Annick Schmitz

tonia.annick.schmitz@uni-weimar.de

1 Bauhaus-Universität Weimar-Biotechnology in Resource Management, Goetheplatz 7/8, 99423 Weimar, Germany present in the cell walls of the genus Ulva. However, with contents ranging from 2 to $60 \%$ in algal dry mass, the availability of these gelling carbohydrates largely depends on the quality of the algal material produced and thus on the production process itself (Kidgell et al. 2019). In this respect, a close look at the specifics of current production systems reveals a noteworthy potential for improvement.

Basically, macroalgae can be cultivated in three types of production systems: marine aquaculture, land-based tank or pond cultivation, and closed photobioreactor systems. Marine aquaculture is widely established but lacks the means to control cultivation parameters (Hafting et al. 2015): Algae growth rates are determined by oceanographic and meteorological parameters as well as the prevailing water quality in the production area (Buck and Grote 2018). Additionally, the crop quantity and quality are increasingly limited by the effects of climate change and ocean acidification (Kelly and Hofmann 2013) as well as proliferating pathogens, epiphytes, or herbivores (Hurd et al. 2014; Hafting et al. 2015; Kerrison et al. 2015; Fernand et al. 2017). These negative factors can be mitigated by cultivating algae in land-based 
tanks or ponds: Both the cultivation parameters and the presence of detrimental organisms can be monitored and partially controlled in these semi-closed systems. However, the key feature of such cultivation systems is their land-based but coastal location due to their constant need for fresh seawater (Pereira et al. 2012, 2013; Hafting et al. 2015). Consequently, both marine aquaculture and land-based tank cultivation compete with often more profitable uses of coastal regions, such as recreational activities, tourism, and fishery - a circumstance that is denominated critical for the development of macroalgae cultivation (Hafting et al. 2015). Overcoming these disadvantages, closed production systems can increase the degree of freedom in the choice of location, the biosecurity of the overall production process, and the value-added potential of the produced algae. Photobioreactor systems allow for the monitoring and fine-tuning of the growth environment and thereby lead to a production outcome predictable in quantity and quality. Albeit, the cultivation of macroalgae in closed photobioreactor systems is currently facing significant challenges preventing an implementation on an industrial scale: In the prototypes developed to date, insufficient temperature control and inadequate light supply limit the achievable growth rates. Also, the lack of an effective recycling strategy for the cultivation medium implies frequent medium changes and thus a seawater supply nearby (Chemodanov et al. 2017; Sebök et al. 2017, 2018; Mhatre et al. 2018).

To summarize, the current need for research revolves around a reliable provision of growth-promoting cultivation parameters for macroalgae production at sites distant from the shore. The aim is, therefore, to develop a closed photobioreactor system enabling full control of abiotic environmental parameters and an effective reconditioning of the cultivation medium. Special focus is laid on the supply of light in adequate intensity and spectrum for macroalgae production using energy-efficient light-emitting diodes (LED).

\section{Materials and methods}

A closed photobioreactor system was designed and implemented for the production of macroalgae in central Germany (Geebesee, Thuringia). To assess the functionality of the overall system, cultivation experiments were undertaken with different algae species over the course of 2 years. The following sections cover the materials and methods used to develop, characterize, and evaluate the invented production system.

\section{Land-based closed photobioreactor system}

The designed photobioreactor system consists of numerous elements selected with regard to the functional requirements and energy efficiency of the macroalgae production process. To allow for a subsequent adaptation to local spatial circumstances or the variation of production quantities, particular attention has been paid to a modular system design. Implementing a basic setup, four breeding modules have been installed together with one conditioning and one system control module on the premises of the Geratal Agrar $\mathrm{GmbH}$ in Gebesee (D). A piping and instrumentation diagram in accordance with EN ISO 10628 is depicted in Fig. 1.

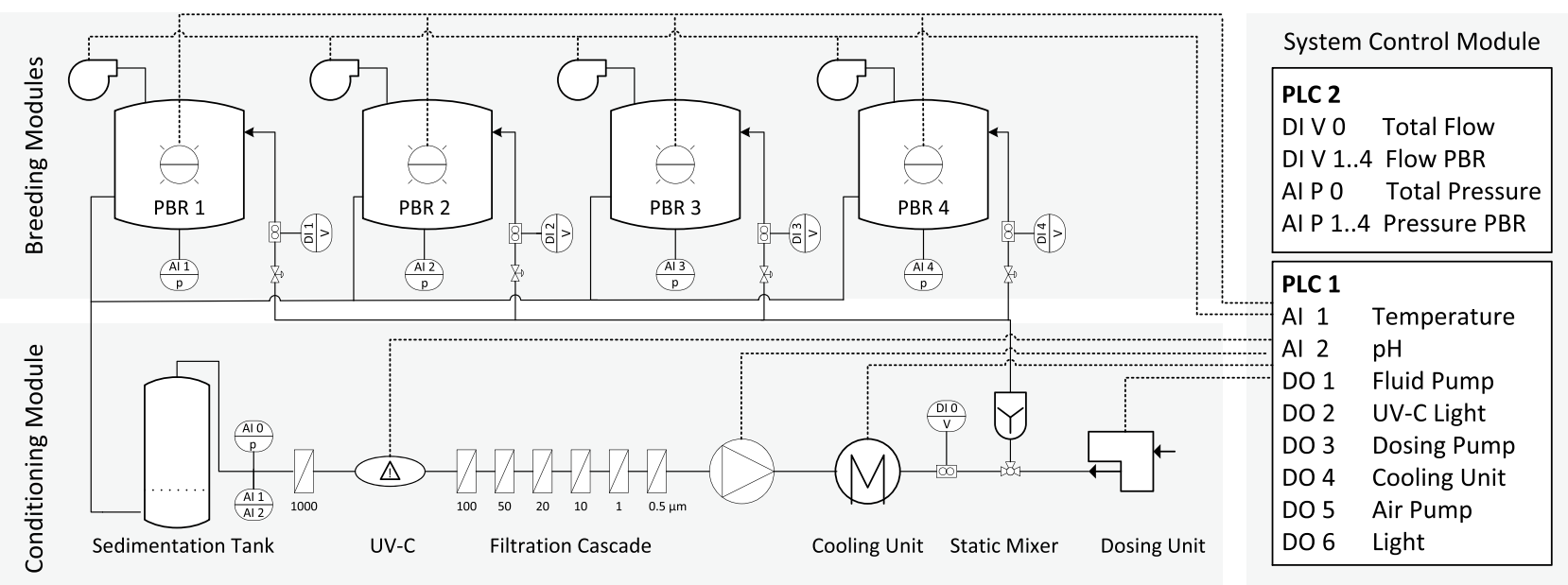

Fig. 1 Piping and instrumentation diagram of the developed photobioreactor system according to EN ISO 10628. The connecting lines between sensors and PLC have been omitted to reduce graphi- cal complexity (PLC, programmable logic controller; AI, analog IN; DI, digital IN; DO, digital OUT) 


\section{Breeding module}

Each breeding module consists of an Intermediate Bulk Container (IBC) tank $(100 \times 120 \times 116 \mathrm{~cm})$ prepared for macroalgae cultivation as depicted in Fig. 2. To enable algae handling and harvesting, the inner bladder of the IBC was cut open and lined with an NR/SBR rubber band $(500 \times 30 \times 0.1 \mathrm{~cm})$ at its top edge. An aluminum plate $(110 \times 130 \times 0.5 \mathrm{~cm})$, reinforced with angle profiles on the upper and lower side, serves as tank cover and can be lifted using a rope (PP, $\varnothing 12 \mathrm{~mm}$ ), and pulley block (Schöco 22B 6:1) attached to the ceiling. To provide for an uplifting flow within the breeding tanks (tumble culture), an aeration pump (AquaForte Air Pump V60, $\dot{V}=$ $3.6 \mathrm{~m}^{3} \mathrm{~h}^{-1}$ ) is connected to the aeration element attached to the underside of the tank lid. The dimensions of this aeration element (PVC pipes, $\varnothing 2 \mathrm{~cm}$ ) have been varied in an iterative development process in order to achieve a uniform, gentle rotation of the algae in the breeding tanks. The implemented structure $(80 \times 60 \times 80 \mathrm{~cm})$ provides 4 outlet openings at a depth of $80 \mathrm{~cm}$ and achieves the desired, slowly rotating flow. Each tank has further been lined with a finely meshed net $(100 \times 100 \times 120 \mathrm{~cm}$, mesh size $1 \mathrm{~mm}$ ), to eliminate risks of pipe clogging due to algae being sucked through the bottom tank valves. To test the influence of light supply on algae growth, different illumination setups have been implemented pairwise in the four breeding tanks: Two tanks (PBR 1 and PBR 2) are equipped with newly developed, submersible LED cylinders (396 LED emitting in 8 wavelength ranges, installed within a DURAN glass cylinder $\varnothing 20 \mathrm{~cm} \times 1.2 \mathrm{~m}$, custom made by Lucelab) allowing for a species-specific light supply in terms of intensity and spectrum. The remaining two tanks (PBR 3 and PBR 4) are fitted with four fluorescent tubes recommended as a light source for aquatic plants by their manufacturer (Dennerle, Trocal T5 Special Plant 39 W).

\section{Conditioning module}

The aim of the conditioning module is to ensure constant abiotic cultivation parameters as well as to minimize the fresh water and artificial sea salt demand of the production process. To this end, each breeding module is connected to the conditioning module through bottom tank valves and a collection pipe leading to a small sedimentation tank (PE, $\varnothing 50 \times 115 \mathrm{~cm})$. This tank is equipped with a perforated plate $(\varnothing 5 \mathrm{~mm}$ ) situated between the water inlets at the bottom level and the outlet positioned at a height of $50 \mathrm{~cm}$. To further purify the cultivation medium from non-sedimenting particles, a cartridge filter cascade $(1000,500,100,50,10,1$, $0.5 \mu \mathrm{m}$, Mahle) and a UV-C unit (Helix Max, Aqua Medic) have been integrated into the conditioning line. After these purification steps, the cultivation medium is being conveyed by a membrane pump $\left(\dot{V}=140 \mathrm{~L} \mathrm{~h}^{-1}\right.$, SHURflo 2088-573534, Keller) to a cooling unit (Titan 4000, Aqua Medic), mixed with a nutrient solution added through a dosing pump (BL10 Black Stone, Hanna Instruments) and homogenized by a static mixer (PVC $\varnothing 25 \mathrm{~mm}$, Kwerk). The conditioning line ends with a central overflow unit from which the cultivation medium is returned evenly and in equal proportions to the breeding tanks. The conditioning module has been designed to recycle the cultivation medium of all four connected breeding tanks on a daily basis. Thus, its recycling capacity sums up to $2800 \mathrm{~L} \mathrm{day}^{-1}$ in total.

\section{System control module}

To improve user-friendliness and operational safety, the photobioreactor system has been automated as far as practicable. With all actuators (nutrient and light supply, cooling unit, and air and fluid pumps) connected to central programmable logic controllers (Controllino Maxi, Conelcom), the amount of work and time required for macroalgae cultivation can be sensibly reduced. In addition, a variety of sensors have been
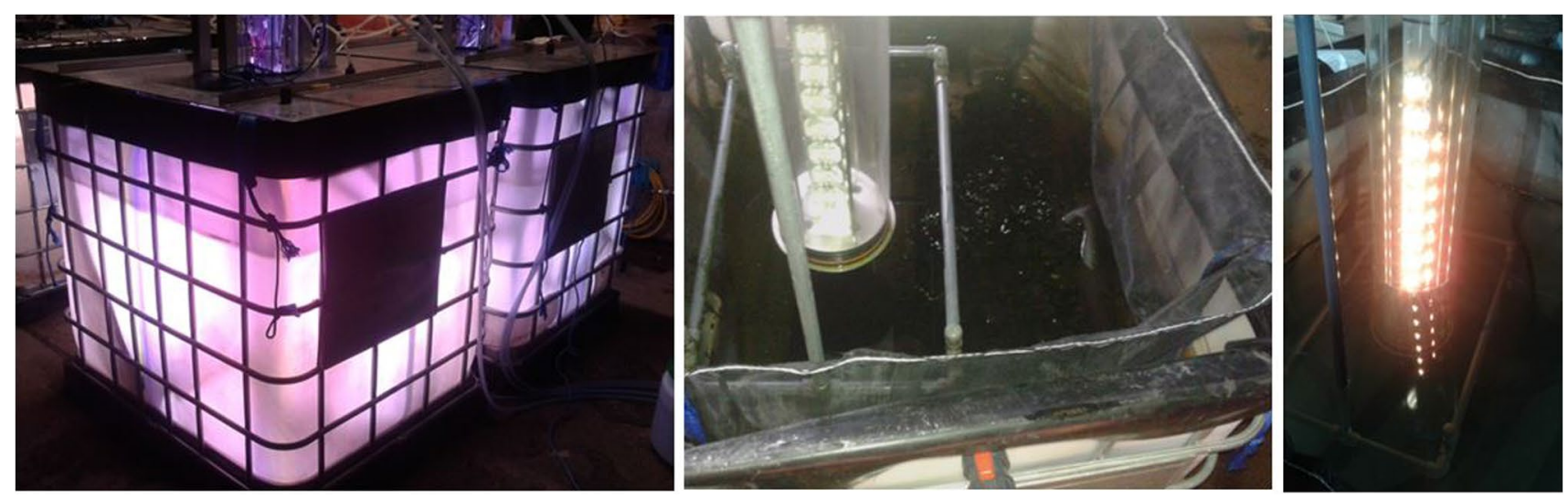

Fig. 2 Breeding module: exterior (left) and interior view (mid, right) with net, aeration element, and LED light source 
installed to improve general plant safety. Special attention was laid on the flow respectively the pressure in the pipes of the conditioning module. In addition to sensors monitoring the flow in the main pipe of the conditioning module, a (process-integrated) calculation of the four tank outflows $\dot{V}_{\text {out }}$ is implemented using the tank-specific inflow $\dot{V}_{\text {in }}$ (measured with FCH-midi-POM, BioTech) and the volume difference in the tanks $\Delta \mathrm{V}$ (via pressure difference $\Delta p$, A-10, WIKA) in the considered time period $\Delta \mathrm{t}$ according to Eq. (1):

$\dot{V}_{\text {out }}=\dot{V}_{\text {in }}-\frac{\Delta V}{\Delta t}$ with $\Delta V=\frac{1}{\rho \bullet g \bullet A} \Delta p$

$\rho=$ medium density, $g=$ gravity, $A=$ sensor area.

An additional pressure sensor (WIKA, A-10) located in the collecting pipe between the sedimentation tank and the filter cascade provides information on the loading of the filter cartridges. The measured values are being transferred to a PC using custom-made software developed in order to monitor the production process. A VPN-secured internet connection enables remote monitoring of the system processes. Additionally, all pressure sensors are linked to an emergency stop switch which allows for an automatic system shut down in the event of increased (and damaging) pressure in the conditioning module. Altogether, the system control module is allowing for constant abiotic cultivation parameters and prevents major damage to the production system.

\section{Cultivation experiments}

All cultivation experiments were undertaken in the developed photobioreactor system presented in Sect. 2.1 with respect to the (known) physiological requirements of the chosen green macroalga Ulva intestinalis. Starting with a description of the origin of the algal biomass, the following subsections give an overview of both the overall experimental setup and the evaluation procedure used.

\section{Macroalgal biomass}

The cultivation experiments are carried out with the alga $U$. intestinalis originating from the Baltic Sea $\left(54^{\circ} 31^{\prime} 13.5^{\prime \prime}\right.$

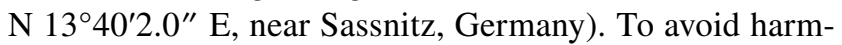
ing wild marine environments, algae are exclusively being collected in large populations and according to the wildlifeprotecting indications summarized by Mac Monagail et al. (2017). On-site, the collected biomass is washed in fresh seawater, freed from sand, and examined for visible signs of grazers or epiphytes. Healthy phylloids are placed in plastic bags $(6 \mathrm{~L})$, wrapped in cloths, and placed in polystyrene boxes $(25 \mathrm{~L})$ cooled with ice cubes. A sensor (Ebro, EBI 20) positioned between the algae bags is used to check the temperature in the cooling box. Temperature is kept below $<18{ }^{\circ} \mathrm{C}$ during the duration of the transport $(\sim 7 \mathrm{~h})$ by gradually adding ice cubes.

\section{Experimental setup}

The cultivation experiments are carried out from July 6 to August 2, 2018 (28 days) in four breeding tanks holding $700 \mathrm{~L}$ of cultivation medium each. The operating schedule of the photobioreactor system provides for nutrient addition once daily, the continuous aeration of all tanks, and a photoperiod of 12:12. The fluid pump - and thus the entire treatment line - pauses four times a day for one hour to reduce pump deterioration. Cultivation conditions are monitored by continuously measuring the system parameters: pressure (WIKA, A-10), the total flow of the cultivation medium (FCH-midi-POM, BioTech), inflow to the individual breeding tanks (FCH-midi-POM, BioTech), the $\mathrm{pH}$ value (Jumo, tecLine 201,020) as well as the temperature of the cultivation medium (PT 100, SWAN) and air (Ebro, EBI 20). In addition, manual measurements of the turbidity (VisoTurb 700 IQ F, WTW) and salinity (areometer, Amarell) of the cultivation medium are carried out on a weekly basis.

Cultivation parameters are adjusted to the physiological requirements of the chosen algal species $U$. intestinalis. With a temperature of $20^{\circ} \mathrm{C}$ and a salinity of 10 , the cultivation medium made out of drinking water and an artificial sea salt mixture (Tropic Marin® CLASSIC) sticks closely to the natural seawater parameters in the collection zone - a marine environment with particularly low salinity. To enhance algal growth rates, initial stocking densities are kept low with $0.13 \mathrm{~g} \mathrm{~L}^{-1}$ (90 $\mathrm{g}$ per tank), and the nutrient supply is raised to $12 \mathrm{mg} \mathrm{NH}_{4}$ day $^{-1}$ and $5.33 \mathrm{mg} \mathrm{PO}_{4}$ day $^{-1}$ using a stock solution based on a universal mineral fertilizer (NovaTec, COMPO). The breeding tanks PBR 1 and PBR 2, equipped with submersible LED light cylinders, are provided with a light spectrum enhanced in the red and blue wavelength ranges (see Fig. 3) and a light intensity of $990 \mu \mathrm{mol}$ photons $\mathrm{m}^{-2} \mathrm{~s}^{-1}$. The breeding modules PBR 3 and PBR 4 are equipped with standard aquarium fluorescent tubes providing a light intensity of $254 \mu \mathrm{mol}$ photons $\mathrm{m}^{-2} \mathrm{~s}^{-1}$ at the water surface and a light spectrum with little intensity in the blue wavelength range, see Fig. 3. Thus, the number of replicates per light setting is $n=2$.

\section{Calculation of biomass growth rate}

Fresh algal biomass is being weighed after using a standardized procedure to reduce adherent water. The algae are repeatedly centrifuged in a conventional salad spinner until the withdrawn water weighs $<1 \mathrm{~g}$. Subsequently, biomass growth is evaluated using the biomass yield $\Delta m$ during the cultivation 


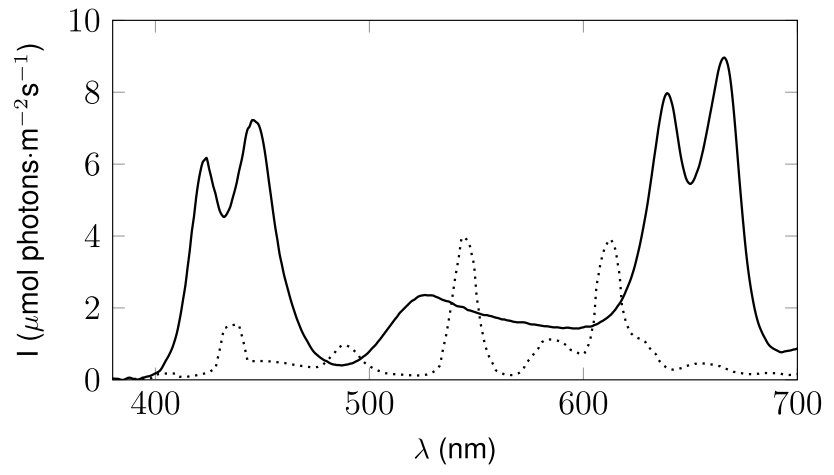

— PBR 1 \& PBR 2 (LED) $\quad$ …... PBR 3 \& PBR 4 (FT)

Fig. 3 Spectra I $(\lambda)$ of the light sources used in cultivation experiments with Ulva intestinalis: LED cylinders in PBR 1 and PBR 2 and fluorescent tubes (FT) in PBR 3 and PBR 4

experiment defined in Eq. (2) and the specific daily growth rate $\mu$ as defined in (Sterner and Elser 2002) with Eq. (3):

$\Delta m=m_{28}-m_{0}$ in $[\mathrm{g}]$

$\mu=\ln \left(\frac{m(t)}{m_{0}}\right) \cdot \frac{1}{t} \cdot 100$ in $\left[\% \mathrm{day}^{-1}\right]$

with the biomass $m(t)$ at time $t$, the initial biomass $m_{0}$ at time $t=0$ day, and the resulting biomass $m_{28}$ at time $t=28$ days. To avoid damaging the delicate, filamentous $U$. intestinalis, biomass weight is only assessed at the beginning ( $t=0$ day) and the end ( $t=28$ days) of the cultivation experiment.

\section{Energy consumption per production cycle}

The energy consumption (EC) of the developed photobioreactor system has been calculated as shown in Eq. (4) using the energy demand (ED) of each system component as specified by its manufacturer and the daily operating hours $(\mathrm{OH})$ during the cultivation process:

$E C=E D \cdot O H$ in $\left[\mathrm{kWh} \mathrm{day}^{-1}\right]$

During the cultivation experiments with $U$. intestinalis, additional measurements were undertaken with a power meter (Brennenstuhl, PM 231 E) for the feedback-controlled (temperature) cooling unit and the newly developed, prototypal LED light source.

\section{Results}

The performance of the newly developed photobioreactor system is being ascertained by evaluating its overall functionality as well as the achieved results regarding the growth

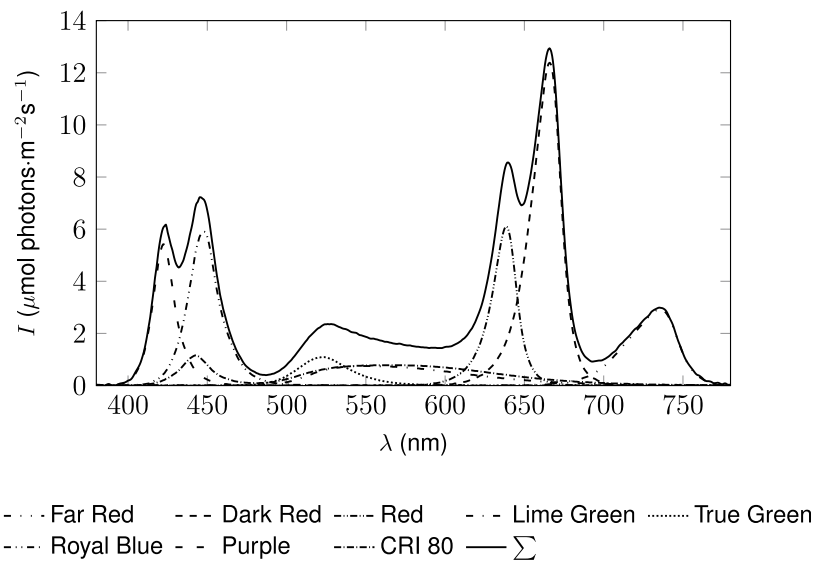

Fig. 4 Spectra of the LED color groups (far-red, dark red, red, lime green, true green, royal blue, purple, CRI 80) used in the newly developed cylindrical light source separately and in sum $(\Sigma)$ at the maximum light intensity

rates and energy consumption during the cultivation experiments with the green alga $U$. intestinalis.

\section{Photobioreactor system}

When developing the presented photobioreactor system, special focus was laid on the provision of optimal abiotic cultivation parameters for marine macroalgae, the reduction of freshwater demand to a minimum, and the realization of an energyefficient production system with limited space demand. The following sections share the observations and findings made during the 24 months of operation of the prototypal plant.

\section{Species-specific cultivation parameters}

The selected process technology allows for the adaptation of parameter values to the physiological needs of the specific macroalgae type being cultivated. The salinity of the cultivation medium can be adjusted manually by adding a defined amount of artificial sea salt (Tropic Marin CLASSIC) to freshwater; the temperature of the cultivation medium can be varied and automatically controlled through the use of a cooling unit; the nutrient supply is fully automated and adjustable using a fertilizer stock solution and a dosing pump. Similarly, the newly developed LED cylinders provide a light quality that can be adjusted between 0 and $1100 \mu \mathrm{mol}$ photons $\mathrm{m}^{-2} \mathrm{~s}^{-1}$ in intensity and between 425 and $730 \mathrm{~nm}$ in the spectrum, see Fig. 4.

Altogether, the possibility of varying the cultivation parameters salinity and temperature of the cultivation medium, as well as the nutrient and light supply to the macroalgae, allows for the production of different species by simulating the conditions in their natural environments. 
Moreover, by adjusting the named parameters closely to the physiological requirements of the cultivated algae, biomass yields and growth rates can - in theory - be maximized and optimized compared to the results achievable in marine aquaculture.

\section{Recirculation of cultivation medium}

As a prerequisite for a closed-loop production system, the recirculation of reconditioned cultivation medium is of crucial importance for the site independence of the developed cultivation plant. Accordingly, great attention was laid on the preservation and regeneration of the quality of the medium, especially in terms of salinity, nutrient content, and translucency. While the first two parameters can easily be readjusted whenever necessary, the latter requires a continuous and effective filtering treatment. Several filtering setups were tested during the 24 months of operation of the prototypal cultivation plant. Two major findings can be summarized as follows:

- The sedimentation tank substantially and reliably increases the functionality and operational safety of the conditioning module. In addition to the removal of particles, it allows for constant pressure levels in the collecting pipe leading to the fluid pump and thereby increases its longevity.

- Constant turbidity values $\leq 1.4 \mathrm{NFU}$ can be guaranteed for at least 12 months of operation when a UV-C unit is being used in addition to a filtering cascade removing particles $\geq 0.5 \mu \mathrm{m}$, see Fig. 5 .

Accordingly, production downtimes for maintenance can be reduced to four times a year and the intervals for total cultivation medium exchange were expanded to once a year.
However, it is important to notice that the water levels and salinity of the cultivation medium need to be adjusted once a month since losses occur through water evaporation and salt deposition on various system components.

\section{Area and volume requirements}

The space requirement of the developed photobioreactor system mainly depends on the number of breeding modules installed. With a basic tank size of $1.2 \mathrm{~m}^{2}$ and an additional $0.5 \mathrm{~m}^{2}$ of floor area needed for maintenance and algae handling, in total $1.7 \mathrm{~m}^{2}$ are required for each breeding module. Considering a minimum height of $3 \mathrm{~m}$ to allow for cover lifting and algae handling, the volume to be envisaged per breeding module remains just under $6 \mathrm{~m}^{3}$. Thus, the space occupied by the four breeding modules installed at Geratal Agrar amounts to $6.8 \mathrm{~m}^{2}$, respectively, $24 \mathrm{~m}^{3}$. In contrast, the conditioning and system control modules account for $4 \mathrm{~m}^{2}$, respectively, $6 \mathrm{~m}^{3}$ together. Thereby, the total space demand for the basic setup of the photobioreactor system presented in this article sums up to $10.8 \mathrm{~m}^{2}$, respectively, $30 \mathrm{~m}^{3}$.

\section{Cultivation experiments}

The developed photobioreactor system has been used for the cultivation of the macroalgae species $U$. intestinalis, Fucus vesiculosus, and Palmaria palmata. However, due to difficulties with the provision of vital algae as initial biomass and technical issues during the cultivation experiments, the experiments carried out with $F$. vesiculosus (temporarily defect light cylinders) and P. palmata (decreased vitality due to transport damage), did not lead to conclusive results. Hence, this article and the following subsections only present the results of the cultivation experiment achieved with the green alga $U$. intestinalis.
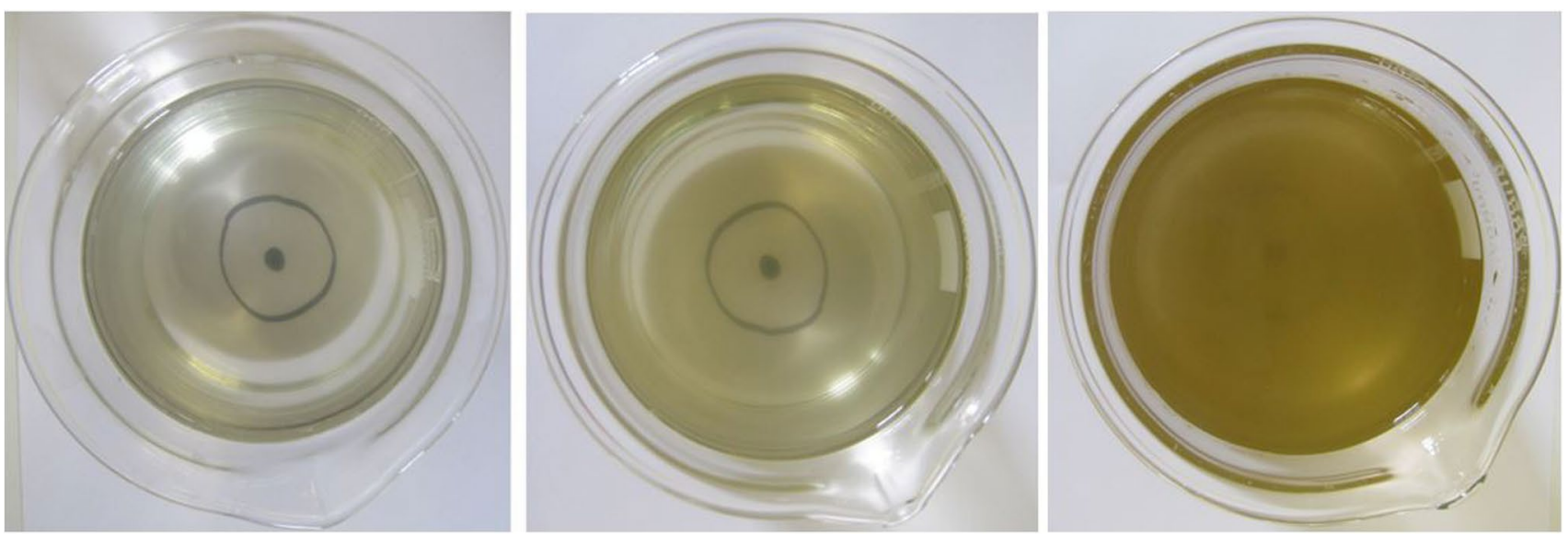

Fig. 5 Cultivation medium (f.l.t.r.): fresh medium; after 12 months when being reconditioned through filtering cascade including UV-C unit; after 4 weeks of operation when being reconditioned with filtering cascade excluding UV-C unit 


\section{Growth rates of Ulva intestinalis}

The cultivation experiments with $U$. intestinalis were started with an identical amount of initial fresh biomass $\left(m_{0}\right)$ in each breeding tank: $90 \mathrm{~g}$ in PBR 1 to PBR 4. After 28 days, depending on the light source installed, the green macroalgae achieved biomass yields of $694.5 \pm 8.5 \mathrm{~g}$ in breeding tanks equipped with submersed LED lights (PBR 1 and PBR 2) compared to $17 \pm 6 \mathrm{~g}$ in those equipped with fluorescent tubes (PBR 3 and PBR 4). The resulting growth rates amount to $7.72 \pm 0.04 \%$ day $^{-1}$ in PBR 1 and PBR 2, respectively, to $0.61 \pm 0.20 \%$ day $^{-1}$ in PBR 3 and PBR 4. Interestingly, the algae also grew on the submersed light cylinders and thus increasingly reduced light supply over the course of time: As depicted in Fig. 6, both cylinders were fully grown over after 28 days. Table 1 summarizes the achieved results with $U$. intestinalis with reference to the light source and intensity provided in each breeding tank. Since all other parameters were kept constant and equal for all four tanks, the light parameters seem of primordial and decisive importance for the productivity of the grown algae.

\section{Electricity consumption}

The energy consumption of the developed photobioreactor system is highly dependant on the chosen cultivation parameter configuration, respectively, the physiological requirements of the macroalgae to be grown. When cultivating the green macroalgae $U$. intestinalis, the electricity consumption per breeding module amounts to $2.71 \mathrm{kWh} \mathrm{day}^{-1}$ when using fluorescent tubes as light source, compared to 5.26 $\mathrm{kWh} \mathrm{day}^{-1}$ when using the newly developed LED cylinders. The conditioning module contributes with a daily electricity demand of $11.82 \mathrm{kWh} \mathrm{day}^{-1}$ to the total energy demand when using the operating schedule described in Sect. 2.2.2. Adding up the energy demand for the sensory and control
Table 1 Results of growth experiments with Ulva intestinalis in the developed photobioreactor system with the initial biomass $\left(m_{0}\right)$, final biomass $\left(m_{28}\right)$, biomass yield $(\Delta m$ in $[\mathrm{g}])$, and the growth rate $(\mu)$ in $\left[\% \cdot\right.$ day $\left.^{-1}\right]$ in the tanks PBR 1 to PBR 4 equipped with submersed LED-light cylinders (LED) or emersed fluorescent tubes (FT) producing a light intensity (I) indicated in $\mu \mathrm{mol}$ photons $\mathrm{m}^{-2} \mathrm{~s}^{-1}$

\begin{tabular}{llllll}
\hline Tank & Light source $(I)$ & $m_{0}$ & $m_{28}$ & $\Delta m$ & $\mu$ \\
\hline PBR 1 & LED (990) & 90 & 793 & 703 & 7.77 \\
PBR 2 & LED (990) & 90 & 776 & 686 & 7.68 \\
PBR 3 & FT (254) & 90 & 101 & 11 & 0.41 \\
PBR 4 & FT (254) & 90 & 113 & 23 & 0.81 \\
\hline
\end{tabular}

components, total consumption of $3.1 \mathrm{kWh} \mathrm{day}^{-1}$ is to be allocated to the system control module. Thus, when cultivating $U$. intestinalis, the actual energy demand of the developed prototypal plant sums up to $30.86 \mathrm{kWh} \mathrm{day}^{-1}$. However, the photobioreactor system would consume $25.76 \mathrm{kWh}$ $\mathrm{day}^{-1}$ in total if all four breeding tanks were equipped with fluorescent tubes as a light source. In contrast, providing an LED light cylinder for each breeding tank would result in increased total energy consumption of $35.96 \mathrm{kWh}$ day $^{-1}$. Table 2 summarises the energy demand, operating hours, and electricity consumption of the system components.

\section{Extrapolation of cultivation results}

To merge the results of the cultivation experiments into key figures suited for extrapolation, the biomass yield achievable in a photobioreactor system either equipped with LED cylinders or fluorescent tubes is put into context with the energy, area, and volume required for its production. Table 3 summarizes the results and emphasizes the positive effects of the LED light source on biomass growth. Despite the higher energy demand compared to fluorescent light tubes, the ratio of biomass yield to energy consumption per growth
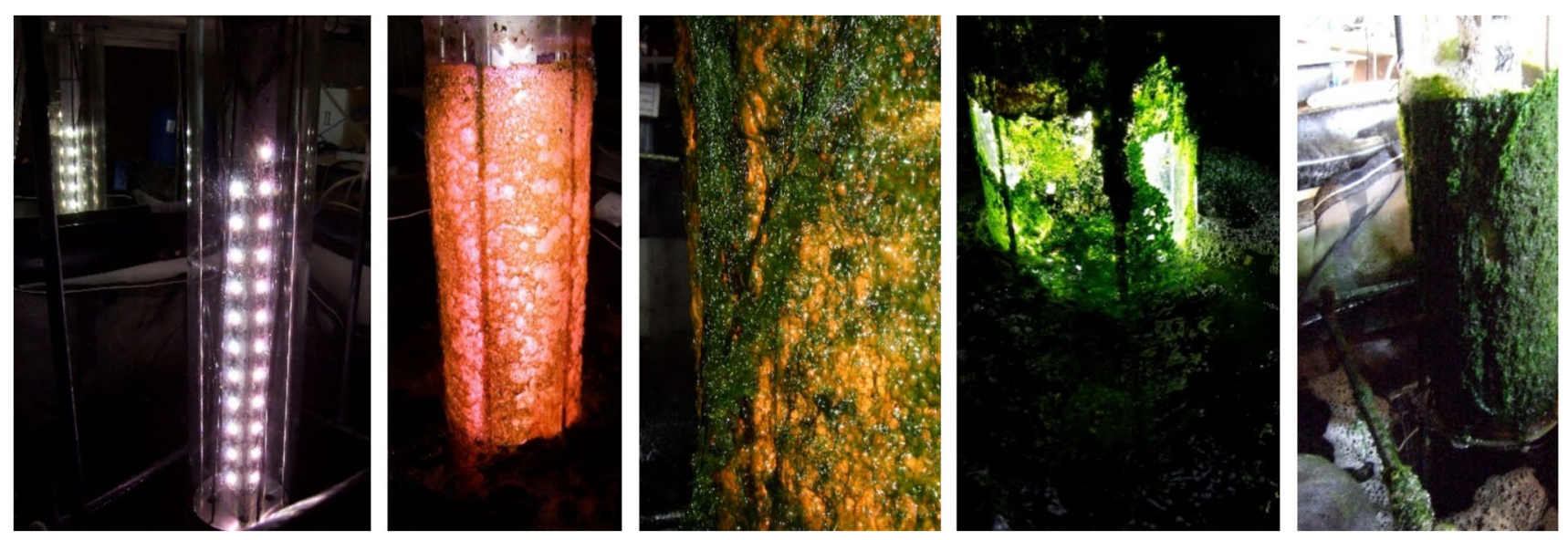

Fig. 6 Ulva intestinalis: biomass growth on the LED cylinders at day 0, 7, 14, 21, and 28 (f.l.t.r.) 
Table 2 Energy demand of main consumers in developed photobioreactor system for the cultivation of Ulva intestinalis. ED, electricity demand in [W]; $\mathrm{OH}$, operating hours in [h/day]; $E C$, electricity consumption in $\left[\mathrm{kWh} \mathrm{day}^{-1}\right]$

\begin{tabular}{llll}
\hline Modules and components & ED & OH & EC \\
\hline Breeding module & & & \\
Air Pump V60 & 35 & 24 & 0.84 \\
Trocal T5 Special Plant & 156 & 12 & 1.87 \\
LED Cylinder & 369 & 12 & 4.42 \\
Conditioning module & & & \\
Helix Max UV Klärer & 18 & 20 & 0.36 \\
SHURflo 2088-573-534 & 156 & 20 & 3.12 \\
Titan 4000 & 417 & 20 & 8.34 \\
System control module & & & \\
Transmitter AMI pH/Redox & 30 & 24 & 0.72 \\
Fritz!Box & 9.3 & 24 & 0.22 \\
PC & 90 & 24 & 2.16 \\
\hline
\end{tabular}

Table 3 Extrapolation of the results with Ulva intestinalis for one growth cycle ( 28 days) in a photobioreactor system equipped with submersed LED-light cylinders (LED) or emersed fluorescent tubes (FT) with the total biomass yield $(\Delta m)$ in $[\mathrm{g}]$ divided through the energy consumption (EC) in $\left[\mathrm{g} \mathrm{kWh}^{-1}\right]$, the area (A) in $\left[\mathrm{g} \mathrm{m}^{-2}\right]$, and the volume $(\mathrm{V})$ in $\left[\mathrm{g} \mathrm{m}^{-3}\right]$

\begin{tabular}{lllll}
\hline PBR system & $\Delta m$ & $\Delta m / \mathrm{EC}$ & $\Delta m / \mathrm{A}$ & $\Delta m / \mathrm{V}$ \\
\hline $4 \times$ LED & 2778 & 2.76 & 257.22 & 92.60 \\
$4 \times \mathrm{FT}$ & 68 & 0.09 & 6.29 & 2.26 \\
\hline
\end{tabular}

cycle (28 days) is 30 times higher when using LED light cylinders for the cultivation of $U$. intestinalis. Similarly, the algae production per area and volume with the LED light source surpasses the yields achievable with fluorescent tubes over 40 times. Equipped with LED cylinders, the developed photobioreactor system can produce roughly $33 \mathrm{~kg}$ of $U$. intestinalis per year on a surface of $10.8 \mathrm{~m}^{2}$ and a volume of $30 \mathrm{~m}^{3}$. This results in a productivity of $3.0 \mathrm{~kg} \mathrm{~m}^{-2}$, respectively, $1.1 \mathrm{~kg} \mathrm{~m}^{-3}$.

\section{Discussion}

Substantial progress toward the provision of growth-promoting cultivation parameters for the production of macroalgae at sites distant from natural seawater is needed to overcome the disadvantages of the cultivation systems known to date. As a step toward this aim, a closed photobioreactor system was developed with the intention to provide optimal abiotic cultivation parameters for macroalgae growth while reducing the freshwater demand of the production system to a minimum. This newly developed system allowed for the production of macroalgae in central Germany - a site distant from natural seawater.

Compared to the photobioreactor systems for macroalgae cultivation constructed to date (Chemodanov et al. 2017; Sebök et al. 2017, 2018; Mhatre et al. 2018), the prototypal plant implemented in Gebesee allows for more comprehensive control of the light and temperature of the parameters, as well as an effective reconditioning and thus recirculation of the cultivation medium. In addition, the sensor-based monitoring and control of the process technology reliably prevents accidents and ensures a high level of user-friendliness. In cultivation experiments with the green algae $U$. intestinalis, the growth rates achieved with submersed LED cylinders just about lie within the range of $6.9-19.40 \%$ day $^{-1}$ documented in the literature for this species in 28-days, labscale experiments in natural seawater, and under natural sunlight (Fong et al. 2004; Ruangchuay et al. 2012). In contrast, the strikingly low growth rates achieved with fluorescent tubes lag behind literature values and thereby affirm the importance of adequate light parameters for macroalgae cultivation. Since the highest growth rates were achieved by Ruangchuay et al. (2012) using reduced stocking densities $\left(0.05 \mathrm{~g} \mathrm{~L}^{-1}\right)$ and increased cultivation temperatures $\left(25^{\circ} \mathrm{C}\right)$, adjusting these abiotic parameters in further cultivation experiments seems promising. In addition, increasing the harvesting frequency in breeding tanks equipped with submersed LED light sources should lead to higher growth rates since the light supply was sensibly decreased from day 14 to 28 due to the light cylinders being grown over by the cultivated algae.

Nevertheless, the energy demand of the newly developed system is to be considered as too high: With $12 \mathrm{MWh}$ per year for a macroalgae production output of $33 \mathrm{~kg}$ in total, the efficiency and profitability of the cultivation system need to be optimized. Looking more closely at the largest energy consumers, it has to be stated that almost $50 \%$ of the total energy consumption is caused by the newly developed LED light source and roughly $23 \%$ by the continuous cooling of the cultivation medium. Since the provision of constant abiotic parameters requires both the provision of light in adequate quality and of a suitable temperature for algae growth, further development efforts should concentrate on these topics. Considerable improvements could for instance be obtained by cooling the cultivation medium through waste heat-driven sorption systems and the implementation of a combined light source using natural sunlight through optical fiber bundles supplemented with an LED light source adjustable in intensity and spectrum.

Altogether, closed production systems such as the developed photobioreactor system can increase both the degree of freedom in the choice of location and the value of the produced macroalgae. However, to achieve the economic viability of these highly technical production systems, further 
investigation should also include fundamental research on optimal cultivation parameters for the production of biochemically active substances such as ulvan as raw materials for pharmaceuticals and cosmetics.

\section{Conclusion}

The developed photobioreactor system allows for comprehensive control of the cultivation conditions and effective treatment of the cultivation medium. Salinity, temperature, light, and nutrient supply can be adapted and maintained according to the physiological needs of different algae species, and the plant is independent of natural seawater. Through the sensor-based control and monitoring of the plant processes, damaging events can be prevented and a high degree of user-friendliness is being achieved. However, the energy demand of the plant is to be reduced and further cultivation experiments should be undertaken to optimize the cultivation parameters in order to maximize the growth rates and the production of biochemically active substances.

Acknowledgements We want to thank Michael Riebesecker for the most valuable technical support during the construction and operation of the photobioreactor system. Also, we are deeply grateful for the advice and guidance regarding light sources and algae physiology to Dr.-Ing. Karin Bieske from the Technische Universität Ilmenau, Prof. Dr. rer. nat. Wolfgang Bilger from the Christian-Albrechts Universität $\mathrm{zu}$ Kiel and the members of the German Academy for Photobiology and Phototechnology (DAfP).

Author contribution All authors contributed to the study's conception and design. Material preparation, data collection, and analysis were performed by Tonia A. Schmitz. The first draft of the manuscript was written by Tonia A. Schmitz and revised by Eckhard Kraft. Funding for the presented work was acquired by Eckhard Kraft and Tonia A. Schmitz. All authors read and approved the final manuscript.

Funding The authors received financial support by the german Fachagentur Nachwachsende Rohstoffe e.V. (FNR). Open Access publishing was enabled and organized by Projekt DEAL.

Data availability The datasets generated and analyzed during the current study are available from the corresponding author on reasonable request.

\section{Declarations}

Conflict of interest The authors declare no competing interest.

Open Access This article is licensed under a Creative Commons Attribution 4.0 International License, which permits use, sharing, adaptation, distribution and reproduction in any medium or format, as long as you give appropriate credit to the original author(s) and the source, provide a link to the Creative Commons licence, and indicate if changes were made. The images or other third party material in this article are included in the article's Creative Commons licence, unless indicated otherwise in a credit line to the material. If material is not included in the article's Creative Commons licence and your intended use is not permitted by statutory regulation or exceeds the permitted use, you will need to obtain permission directly from the copyright holder. To view a copy of this licence, visit http://creativecommons.org/licenses/by/4.0/.

\section{References}

Buck B, Grote B (2018) Seaweed in high-energy environments. In: Charrier B, Wichard T, Reddy C (eds) Protocols for macroalgae research. CRC Press, Boca Raton, pp 3-36

Budd G, Pizzola P (2008) Ulva intestinalis - gut weed. In: TylerWalters H, Hiscock K. (eds) Marine life information network: biology and sensitivity key information reviews, marine biological association of the United Kingdom, Plymouth, https:// www.marlin.ac.uk/species/detail/1469, viewed on 10 May 2021

Chemodanov A, Robin A, Golberg A (2017) Design of marine macroalgae photobioreactor integrated into building to support seagriculture for biorefinery and bioeconomy. Bioresour Technol 241:1084-1093

Circuncisão A, Catarino M, Cardoso S, Silva A (2018) Minerals from macroalgae origin: health benefits and risks for consumers. Mar Drugs 16:400

FAO (2018) The state of world fisheries and aquaculture 2018 - meeting the sustainable development goals. Report. FAO, Rome

Farasat M, Khavari-Nejad R, Nabavi S, Namjoyan F (2014) Antioxidant activity, total phenolics and flavonoid contents of some edible green seaweeds from northern coasts of the Persian Gulf. Iranian J Pharmaceut Res 13:163-170

Fernand F, Israel A, Skjermo J, Wichard T, Timmermans K, Golberg A (2017) Off- shore macroalgae biomass for bioenergy production: environmental aspects, technological achievements and challenges. Renew Sust Energy Rev 75:35-45

Fong P, Fong J, Fong C (2004) Growth, nutrient storage, and release of dissolved organic nitrogen by Enteromorpha intestinalis in response to pulses of nitrogen and phosphorus. Aquat Bot 78:83-95

Hafting J, Craigie J, Stengel D, Loureiro R, Buschmann A, Yarish C, Edwards M, Critchley A (2015) Prospects and challenges for industrial production of seaweed bioactives. J Phycol 51:821-837

Hurd C, Harrison P, Bischof K, Lobban C (2014) Seaweed ecology and physiology, 2nd edn. Cambridge University Press, Cambridge

Kelly M, Hofmann G (2013) Adaptation and the physiology of ocean acidification. Funct Ecol 27:980-990

Kerrison P, Stanley M, Edwards M, Black K, Hughes A (2015) The cultivation of European kelp for bioenergy: site and species selection. Biomass Bioenergy 80:229-242

Kidgell J, Magnusson M, de Nys R, Glasson C (2019) Ulvan: a systematic review of extraction, composition and function. Algal Res 39:101422

Kosanić M, Ranković B, Stanojkovic T (2015) Biological activities of two macroalgae from Adriatic coast of Montenegro. Saudi J Biol Sci 22:390-397,

Mac Monagail M, Cornish L, Morrison L, Araújo R, Critchley A (2017) Sustainable harvesting of wild seaweed resources. Eur J Phycol 52:371-390

Mhatre A, Navale M, Trivedi N, Pandit R, Lali A (2018) Pilot scale flat panel photobioreactor system for mass production of Ulva lactuca (Chlorophyta). Bioresour Technol 249:582-591 
Murphy C, Hotchkiss S, Worthington J, McKeown S (2014) The potential of seaweed as a source of drugs for use in cancer chemotherapy. J Appl Phycol 26:2211-2264

Pereira R, Yarisch C, Chritchley A (2012) Seaweed aquaculture for human foods, in land-based and imta systems. In: Meyers R (ed) Encyclopedia of Sustainability Science and Technology. Springer, New York, pp 9109-9128

Pereira R, Yarish C, Critchley A (2013) Seaweed aquaculture for human foods in land-based and IMTA systems. In: Savin R, Costa-Pierce BA, Misztal I, Whitelaw CBA (eds) Christou P. Springer, New York pp, pp 1405-1424

Ruangchuay R, Dahamat S, Chirapat A, Notoya M (2012) Effects of culture conditions on the growth and reproduction of gut weed, Ulva intestinalis Linnaeus (Ulvales, Chlorophyta). Songklanakarin J Sci Technol 34:501-507
Sebök S, Herppich W, Hanelt D (2017) Development of an innovative ring-shaped cultivation system for a land-based cultivation of marine macroalgae. Aquacult Eng 77:33-41

Sebök S, Herppich W, Hanelt D (2018) Outdoor cultivation of Ulva lactuca in a recently developed ring-shaped photobioreactor: effects of elevated $\mathrm{CO}_{2}$ concentration on growth and photosynthetic performance. Bot Mar 62:179-190

Sterner RW, Elser JJ (2002) Ecological stoichiometry - the biology of elements from molecules to the biosphere. Princeton University Press

Publisher's note Springer Nature remains neutral with regard to jurisdictional claims in published maps and institutional affiliations. 